\section{Questión}

Periodismo / Comunicación ISSN 1669-6581
- Av. $44 \mathrm{~N}^{\circ} 676,1^{\circ}$ piso

CP 1900 - La Plata - Argentina

(4) www.perio.unlp.edu.ar/question

Cuando el tiempo sea solo rapidez

Alan Lell

https://doi.org/10.24215/16696581e360

\title{
Cuando el tiempo sea solo rapidez
}

\author{
¿Fin de época o paréntesis existencial?
}

\section{When time is only fast}

End of era or existential parenthesis?

Alan Lell

Buenos Aires, 1988. Es escritor y estudia Comunicación Audiovisual en la Universidad Nacional de San Martín. Participa del taller de lectura y escritura Heterónimos. Como escritor de ficción, su cuento Invocación fue publicado por la revista alemana Lado Berlín en mayo del 2020. Ademas, su cuento El aplastamiento obtuvo el primer premio en el IV Certamen Nacional de Poesía y Cuento Breve en Homenaje a Hugo Gola, del 2019. Uno de sus poemas integra la antología Poetas latinoamericanos, publicada por Es autor del blog Caminar conociendo (https://caminarconociendo.wordpress.com), en donde publica crónicas, ensayos y ficción. alanlell88@gmail.com http://orcid.org/0000-0002-8938-974X

\section{Palabras clave}

Tiempo - Instantaneidad - Estado - Simultaneidad

\section{Keywords}

Time - Instantity - State - Concurrency

¿Para qué? ¿Hacia dónde? ¿Después qué? Estas son las preguntas que según Martin Heidegger nos haríamos "cuando el tiempo sea solo rapidez, instantaneidad y simultaneidad"i. Bueno, ese tiempo llegó hace rato, probablemente con la caída del Muro de Berlín en 1989 y el consiguiente triunfo del neoliberalismo como ideología global. Hubo, luego, dos acontecimientos 
más a los que podríamos acudir para explicar las bases que cimentaron esta época. Esta época que con la pandemia pareciera entrar en un interregno universal. Paradójicamente, uno de estos acontecimientos fue definido en términos de un no-acontecimiento. Jean Baudrillard, sobre la Guerra del Golfo (en 1991), escribió un ensayo breve pero punzante titulado La Guerra del Golfo no ha tenido lugar. Este no-tener-lugar no se refería a una inexistencia fáctica de la guerra, sino a un simulacro del conflicto fundado en una "lógica hiperrealista de disuasión de lo real mediante lo virtual"ii. ¿Suena conocido? Incluso hay que tener en cuenta que lo virtual, a fines del siglo pasado, era solo o fundamentalmente la televisión. Después, la caída de las Torres Gemelas en el 2001 fue, en este caso sí, todo un acontecimiento. Ya no tenía sentido hablar de simulacro. La realidad había golpeado nada menos que en Nueva York, el núcleo de la hegemonía global.

Si la caída del Muro fue el mito fundacional del neoliberalismo y la Guerra del Golfo uno de sus correlatos mediático-virtuales, la caída de las Torres Gemelas comenzó a definir el escenario geopolítico en que toda esta vorágine ocurriría. Hasta la crisis financiera del 2008, que en palabras del economista francés Thomas Piketty fue "la primera crisis del capitalismo patrimonial globalizado del siglo XXI"iii, este escenario funcionaba dentro de una burbuja idílica, que muy pronto estallaría por los aires. A la salvaguarda de este nuevo vacío, una vez que la membrana de detergente se deshizo en un instante, acudieron nada más ni nada menos que los Estadosnación. A diferencia de la crisis de 1929, esta vez, "los gobiernos y los bancos centrales de los países ricos no permitieron que el sistema financiero se desplomara y aceptaron crear la liquidez necesaria para evitar las cascadas de quiebras bancarias"iv. Según Paul Preciado, filósofo español, estaba sucediendo "lo que nunca habríamos imaginado: el neoliberalismo no solo no cuestionaba los Estados-nación, sino que además establecía una alianza con sus segmentos políticos más conservadores"v.

Este recorrido fugaz nos permite pensar la particularidad de nuestra época. La pandemia del coronavirus no nos afecta de manera abstracta, sino que inscribe en un determinado contexto económico y político mundial. No hacen falta demasiadas pruebas para constatar que desde ese ya lejano 1989 estamos en los tiempos de los que hablaba Heidegger. Sin el flujo incesante, irrestricto de circulación de mercancías, personas e información que es connatural al proceso de globalización neoliberal, esta historia hubiera sido otra. Sin la sobredeterminación mediática, sin la virtualidad, sin internet en todos los rincones del planeta, probablemente también. La revalorización de los Estados-nación, por otra parte, ha cobrado un matiz diferente según cada 
región. En la Unión Europea, por ejemplo, lo que sucede es una gran paradoja. Se había constituido la utopía de una Europa que en su interior funcionaba en forma abierta. Era, en escala continental, un modelo reducido de lo que exigía la ideología neoliberal en el mundo. Pero esta apertura interior contrastaba violentamente con unas fronteras cerradas a los migrantes y los extranjeros. "Cerramos las fronteras en Grecia, construimos los mayores centros de detención a cielo abierto de la historia de las islas que bordean Turquía y el Mediterráneo y fantaseamos que así conseguiríamos una forma de inmunidad"vi, escribe Paul Preciado, en un artículo publicado en El País el 28 de marzo de 2020. Nada lejos de aquella tesis sartreana sobre el colonialismo que afirmaba que los europeos se habían hecho a sí mismos fabricando esclavos y monstruos. En Sudamérica las experiencias son más heterogéneas. Si en la primera década del siglo XXI primó una lógica de la integración regional, auspiciada fundamentalmente por el Mercosur y por la Unasur, el coronavirus llegó a nuestras tierras en un contexto muy diferente, caracterizado por una fragmentación y una desarticulación en crecimiento. $Y$ todo indicaría que, al menos en una etapa inicial, la desglobalización a la que arrastra indefectiblemente la pandemia, no hará más que agudizar esas diferencias.

¿Para qué? ¿Hacia dónde? ¿Después qué?, nos preguntamos ahora, mirando por la ventana las calles vacías. Nos preguntamos también si no es demasiado tarde para la filosofía. Pero la filosofía suele tener ese pequeño desfasaje temporal, siempre llega un poco después de los acontecimientos. Es su naturaleza. Por eso el planteo de Heidegger podría ser hasta un contrasentido: ¿cómo hacerse preguntas en la rapidez, la instantaneidad y la simultaneidad? Es decir, ¿cómo el neoliberalismo iba a pensarse a sí mismo en el vértigo de su propio funcionamiento? Fue necesario que el ruido ensordecedor de la máquina se detuviera, que el interruptor al fin se bajara, para poder pensar.

El problema que se nos presenta, como puede observarse, se basa esta vez en un nuevo desequilibrio. En la medida en que el coronavirus nos obligó a tomar conciencia del mundo en el que vivimos, ese mundo se detuvo. En Europa, en América, en Asia. Ahora somos ciudadanos con pensamiento crítico: pero ese pensamiento se dirige a un objeto inerte, a una materia opaca. Nuestra soberanía consiste en una coexistencia elemental con las cosas de nuestra casa, y si salimos a la calle, aun si tenemos que trabajar porque pertenecemos a los servicios esenciales o porque no tenemos otra alternativa, nuestra acción social se restringe a los límites de nuestro cuerpo. ¡No vayamos más allá de nuestra cara, no vayamos más allá de nuestras manos! De la 
noche a la mañana, entramos sin darnos cuenta en un solipsismo sanitarista, en una mezcla de George Berkeley con Michel Foucault.

Pero esto no significa que hayamos caído en una interioridad pura. Todo lo contrario: el sentido de todo, más que nunca, está afuera. Solo que este afuera ya no es el mismo que antes. Si el coronavirus se produjo y circula en una determinada forma de organización social y económica, nuestro cuerpo también es el producto de esa especificidad. Aunque estemos adentro de casa, la biopolítica sigue actuando en nosotros. Paul Preciado dice en su artículo que las fronteras en Europa se han reconvertido. "La Covid-19 ha desplazado las políticas de la frontera que estaban teniendo lugar en el territorio nacional o en el superterritorio europeo hasta el cuerpo individual"vii. Y luego, con gran lucidez: "La nueva frontera es la mascarilla. El aire que respiras debe ser solo tuyo. La nueva frontera es tu epidermis"viii.

¿Cómo pensar, con todos estos elementos, el devenir de nuestra vida política? ¿Cómo pensar nuestra democracia? La referencia a un pensador europeo no es antojadiza. Así como la funesta experiencia de Europa nos dio a los argentinos un margen de tiempo para organizarnos mejor frente al avance de la pandemia, sus ideas también nos pueden ser útiles. Incluso aquellas ideas que creemos equivocadas: "Esta técnica no ha mostrado aún pruebas de eficacia total"ix, concluye Paul Preciado al referirse a las medidas de aislamiento que casi todos los países han tomado, con mayor o menor nivel de restricciones. Nuestra pregunta es: ¿no es acaso lo único que hasta ahora ha mostrado pruebas de eficacia? ¿Y que significaría "total" en este contexto? Cualquier tipo de sentencia definitiva parece, ahora más que nunca, una irresponsabilidad. $\mathrm{Si}$ estamos en un fin de época o en un paréntesis es algo incierto. Argentina, un país que pertenece a la periferia de esa lógica neoliberal que se cristalizó en los noventa, un país que arrastra una pobreza estructural producto de otras viejas dependencias, está haciendo lo que puede con lo que tiene. Y lo que tiene es también el resultado de la gestión que degradó el Ministerio de Salud a Secretaría de Salud, entre otros menoscabos deliberados. Si hay algo que justamente debe surgir de toda esta debacle, de esta emergencia global en la que estamos inmersos, es una inexorable revalorización del Estado y de la Salud Pública. ¿Hacia dónde?, preguntábamos al comienzo. Hacia ahí. Hacia esa revalorización. 


\section{Notas}

' Martin Heidegger, Introducción a la metafísica, Gedisa, Barcelona, 2001, pp. 42-43.

ii Jean Baudrillard, La guerra del Golfo no ha tenido lugar, Anagrama, Barcelona, 2001 p. 15.

iii Thomas Piketty, El capital en el siglo XXI, Fondo de Cultura Económica, Buenos Aires, 2014, p. 521.

iv Ibíd., p. 520.

$\checkmark$ Paul B. Preciado, Un apartamento en Urano, Anagrama, Buenos Aires, 2019, p. 35.

vi Paul B. Preciado (28/03/2020), Covid-19: Aprendiendo del virus. Barcelona: El País. https://elpais.com/elpais/2020/03/27/opinion/1585316952 026489.html.

vii Ibíd.

viii Ibíd.

ix Ibíd. 